\title{
Прозрачность раскрытия информации российскими компаниями: обзор докладов, представленных на Второй Международной конференции «Корпоративное управление и устойчивое развитие бизнеса: стратегические роли советов директоров»
}

\author{
Зинкевич Н.В. ${ }^{35}$
}

В последние годы все больше российских компаний выходят на международные рынки капитала. Для привлечения средств зарубежных инвесторов компании необходимо соответствовать высоким стандартам корпоративного управления, одной из составляющей которого является информационная прозрачность. Тем не менее проведенное специалистами агентства Standard\&Poоr's исследование свидетельствует, что уровень прозрачности российских компаний стагнирует. Возможным объяснением этой тенденции служит феномен "ресурсного проклятия», описанный Дурневым А. и Гуриевым С. С другой стороны, как показывает в своей работе Сеттлз А., успешность размещения ценных бумаг за рубежом положительно зависит от уровня раскрытия информации российскими компаниями.

\section{Введение}

Степень прозрачности фирмы является важной частью системы ее корпоративного управления. Своевременность и доступность информации о деятельности фирмы чрезвычайно важны для существующих и потенциальных инвесторов, поскольку позволяют им принимать верные решения и уменьшать возможные потери от экспроприации со стороны менеджмента.

Корпорация в теории корпоративного управления рассматривается как набор контрактов между владельцами (акционерами) и советом директоров, советом директоров и менеджерами, причем последние не всегда руководствуются благом собственников, а стремятся принимать решения в собственных интересах. Поскольку менеджмент является информированной стороной, а владельцы, если они не занимаются непосредственным управлением компанией, - слабо информированной, возникает классический конфликт принципал - агент.

Подробное и своевременное раскрытие компанией информации о различных аспектах своей деятельности, как-то финансовые показатели, степень концентрации собственников, состав и вознаграждение членов совета директоров, уменьшает степень асимметрии информации и ослабляет негативные последствия конфликта агента и принципала. Как отметил Сеттлз А. в своем исследовании «Изменение качества корпоративного управления вследствие выхода на международные рынки капитала» («The Corporate Governance Changes Due to Exposure to the International Capital Market») [2007], от более полного раскрытия информации выигрывают не только потенциальные инвесторы-принципалы, желающие инвестировать в фирму, но и агенты-инсайдеры - менеджмент и существующие крупные собственники. Высокое качество корпоративного управления и раскрытия информации позволяют инвесторам судить не только о прибыльности компании, но также и об отношении к будущим акционерам, особенно миноритарным. Вследствие этого компании с

\footnotetext{
35 Студентка магистратуры факультета экономики ГУ-ВШЭ, программа «Стратегическое управление финансами фирмы». Выпускница бакалавриата факультета экономики ГУ-ВШЭ, 2006 г., специализация «Экономика и финансы фирмы».
} 
большей информационной прозрачностью привлекают внимание инвесторов и имеют более высокую стоимость.

Казалось бы, все корпорации должны стремиться к как можно более высокому уровню информационной прозрачности, поскольку связанные с ее достижением затраты (например, оплата услуг аудиторов) существенно меньше выгод. Однако исследование, проведенное специалистами Службы рейтингов корпоративного управления Standard\&Poor's (S\&P) «Исследование информационной прозрачности российских компаний в 2007 г.: Значительные изменения в десятке лидеров» - показало, что индекс транспарентности российских компаний за год возрос лишь незначительно (с 53,5 процентных пунктов до 54,6 процентных пунктов), причем в основном за счет компаний, вышедших в этом году на IPO. Индекс прозрачности компаний нефтегазовой отрасли не вырос вовсе; характерно и то, что зарубежные IPO российских компаний переместились с американских бирж с их более строгими требованиями на LSE.

Специалисты S\&P не дают объяснения такой стагнации, но частично она может быть обусловлена явлением, описанным в работе Дурнева А. и Гуриева С. «Ресурсное проклятье: воздействие информационной прозрачности корпораций» («The Resource Curse: A Corporate Transparency Channel»). Авторы рассматривают простую модель, в рамках которой фирмы сталкиваются с необходимостью балансировать выгоды от повышения прозрачности (рост стоимости и удешевление привлечения капитала) и угрозы (экспроприация части прибылей или всей компании государством). Угроза конфискации собственности заставляет владельцев и менеджмент компании раскрывать информацию по минимуму, чтобы «грабительское» (predatory) государство не узнало об истинном уровне прибыльности компании и не воспользовалось искушением национализировать ее.

Сеттлз А., с другой стороны, утверждает, что необходимость привлечения финансирования с международных рынков путем IPO, SPO и выпуска еврооблигаций должно вести к постепенному повышению качества корпоративного управления и раскрытию информации российскими компаниями, поскольку это позволяет повысить стоимость. Заман М. в работе 2005 г. «Сближение практик корпоративного управления в Европе: концепция аудиторских комитетов» («Convergence in European Corporate Governance: The Audit Committee Concept») находит подтверждение тому факту, что практики корпоративного управления европейских стран со временем улучшаются и приближаются к англосаксонской модели. Это связано с тем, что LSE и американские биржи являются наиболее привлекательными площадками для размещения; а также с положительным влиянием аудиторов на корпоративное управление и информационную прозрачность. Однако, прежде чем подробно рассматривать аргументы различных авторов, опишем подходы к определению качества раскрытия информации компаниями (информационной прозрачности).

\section{Измерение информационной прозрачности}

\section{Методика службы рейтингов $S \& P$}

Для оценки степени информационной прозрачности S\&P использует набор критериев, состоящий из шести разделов. Состав разделов следующий:

Компонент 1 - структура собственности (количество и номинальная стоимость выпущенных акций, информация о крупнейшем акционере, о держателях всех крупных пакетов акций, пакеты акций в собственности менеджмента и директоров и другие критерии).

Компонент 2 - права акционеров (содержание Кодекса или Положения о корпоративном управлении, порядок созыва акционерами внеочередных общих собраний, документально оформленная дивидендная политика, политика раскрытия информации и другие критерии). 
Компонент 3 - финансовая информация (учетная политика, годовая отчетность в соответствии с международными стандартами и наличие заключения независимого аудитора, методы оценки активов, список аффилированных компаний, сегментный анализ по видам деятельности и другие критерии).

Компонент 4 - операционная информация (информация о видах деятельности компании, объемы производства в натуральном выражении, показатели производства, позволяющие сравнить компанию с конкурентами, показатели эффективности и другие критерии).

> Компонент 5- информащия о совете директоров и менеджменте (список членов совета директоров, данные о текущих местах их работы и должностях, о роли совета директоров в работе компании, список комитетов при совете директоров и другие критерии).

Компонент 6 - вознаграждение менеджмента и членов совета директоров (форма вознаграждения, процесс принятия решений о вознаграждении, информация о привязке вознаграждений к результатам работы компании, детальная информация о величине вознаграждения).

В общей сложности анкета исследования насчитывает 108 пунктов.

B системе весов S\&P само наличие информации по каждому пункту списка давало 80\% максимального балла. Информация может содержаться в любом из трех источников общедоступной информации: в годовых отчетах (вместе с финансовой отчетностью и примечаниями к ней, а также материалами к собранию акционеров), на веб-сайтах компаний, в отчетности, предоставляемой в регулирующие органы (в ФСФР, а для компаний, имеющих листинг на зарубежных площадках, - в регулирующие органы соответствующих стран). Если информация по критерию содержится и в двух других источниках, компания получает еще по 10\% балла за каждый источник. Дублирование информации повышает ее доступность для инвестора, но оценивается намного ниже, чем сам факт наличия информации.

Большое значение для инвесторов имеет своевременность раскрытия информации, поскольку полученная слишком поздно информация становится нерелевантной для принятия решений. Исследование S\&P проводилось по состоянию на 10 августа 2007 г., вся информация, полученная после этой даты, не учитывалась при оценке уровня прозрачности, поскольку она появилась позже, чем через 7 месяцев после окончания отчетного года. По той же причине не учитывались внесенные позже даты исследования поправки и обновления в отчетность.

Поскольку специалисты S\&P оценивали раскрытие информации с точки зрения международного инвестора, учитывался также факт раскрытия информации на английском языке.

Специалисты S\&P отмечают, что эталоном своевременной публикации отчетности является срок 4 месяца по окончании отчетного года. Однако они учитывают «российские реалии» и оценивают полным баллом публикацию аудированной отчетности до проведения годового общего собрания акционеров.

Исследование S\&P использует формальные критерии оценки информационной прозрачности. Само по себе знание инвесторами состава совета директоров и их вознаграждения, дивидендной политики компании еще не гарантирует отсутствия ущемления их интересов со стороны менеджмента, директоров и крупных собственников. Ряд исследователей отмечают, что значение индекса информационной прозрачности S\&P не оказывает ожидаемого положительного воздействия на стоимость компании. Наоборот, воздействие оказывается негативным и значимым при контроле на такие переменные, как эффективность (прибыльность) деятельности компании ${ }^{36}$.

Возможно, нужны менее формальные меры транспаретности, учитывающие способность инсайдеров манипулировать имеющейся у них информацией.

\footnotetext{
${ }^{36}$ Black B.S., Love I., Rachinsky A. Corporate Governance and Firms' Market Values: Time Series Evidence from Russia / Emerging Markets Review, 2006, № 7, p. 361—379. 
Методика измерения непрозрачности Дурнева А. и Гуриева С.

Вместо транспарентности Дурнев А. и Гуриев С. измеряют обратный показатель непрозрачность (орасіty). Хотя для эмпирического тестирования основных зависимостей в их работах используются отраслевые данные, непрозрачность измеряется на уровне фирм. Она включает три компонента: непрозрачность отчетности (accounting opacity), инсайдерскую непрозрачность (insider opacity), информационную непрозрачность (informational opacity).

Непрозрачность отчетности характеризует качество данных о прибыльности, публикуемых в официальной отчетности компании. Высокая степень непрозрачности означает, что менеджмент использует различные техники управления прибыльностью (earnings management), чтобы спрятать прибыль. Дурнев А. и Гуриев С. определяют непрозрачность как отклонение накопленного прироста капитала компании от его «эталонного» значения. Накопленный прирост (ТСА) определяется формулой:

$$
T C A=\triangle C A-\triangle C L-\triangle C a s h+\triangle S T D,
$$

где $\mathrm{CA}$ и $\mathrm{CL}$ - текущие активы и текущие обязательства соответственно,

Cash - денежные средства на балансе,

STD - краткосрочный долг и текущая часть долгосрочного долга.

В отсутствие манипуляций с отчетностью ТСА должны определяться приростом продаж, а также стоимости постоянных активов - зданий, земли, машин и оборудования. Соответственно остатки в регрессии ТСА на два этих параметра являются мерой искажения отчетности. Непрозрачность отчетности измеряется как стандартное отклонение остатков регрессии.

Инсайдерская непрозрачность измеряет общий уровень информационной асимметрии, присущий компании. Для ее оценки авторы используют модель, предложенную Llorente et.al. [2002]. Инвесторы в ней делятся на две категории: инсайдеры, получающие более точную и оперативную информацию о доходности акции, и аутсайдеры. Если к инсайдерам поступает негативная информация о результатах компании, они начинают сбрасывать акции, однако вначале информация только частично отразится в стоимости акции. Поскольку не все инвесторы осведомлены, цена акции будет постепенно снижаться в течение всего периода наблюдения, прежде чем негативная информация будет полностью учтена в ней. Аналогичное заключение верно и для положительной инсайдерской информации: ввиду ее постепенного распространения несколько периодов с положительной доходностью будут следовать один за другим.

Положительная автокорреляция доходности акций, предсказанная этой моделью, должна быть особенно сильной при высоком объеме торгов, так как он обычно наблюдается при сделках с важной инсайдерской информацией. Соответственно чем сильнее положительная автокорреляция, тем выше уровень асимметрии между инсайдерами и аутсайдерами и тем выше непрозрачность.

Для оценки непрозрачности строится регрессия:

$$
R_{t+1}=a+c_{1} R_{t}+c_{2} R_{t} V_{t}+\varepsilon_{t}
$$

где $\mathrm{R}_{\mathrm{t}}$ - доходность акций фирмы в период $\mathrm{t}$,

$\mathrm{V}_{\mathrm{t}}$ - объем торгов в период $\mathrm{t}$.

Величина коэффициента $c_{2}$ отражает степень инсайдерской непрозрачности, присущей данной компании.

Информационная непрозрачность измеряется через корреляцию доходности акций компании с рыночным индексом. Дурнев А. и Гуриев С. отмечают, что в случае сильной взаимосвязи с движениями рыночного индекса котировки акций компании содержат мало информации относительно деятельности компании. И наоборот, при слабой корреляции цены, очевидно, отражают специфическую информацию о фирме. Информационная непрозрачность оценивается на основе регрессии: 


$$
r_{t}=a+\beta_{1} r_{m t}+\beta_{2} r_{U S t}+\varepsilon_{t},
$$

где $\mathrm{r}_{\mathrm{t}}$ - доходность акций компании,

$\mathrm{r}_{\mathrm{mt}}-$ доходность рыночного индекса той страны, к которой относится компания,

$\mathrm{r}_{\mathrm{Ust}}$ - доходность рыночного индекса США (S\&P).

Чем выше объясняющая сила регрессии (3) (eе $\mathrm{R}^{2}$ ), тем выше информационная непрозрачность $(\mathrm{Op})$. Последняя изменяется как разница между объясненной долей дисперсии доходности и ее необъясненной частью:

$$
O p=\ln \left(R^{2}\right)-\ln \left(1-R^{2}\right) .
$$

Поскольку меры непрозрачности коррелированы между собой, для устранения мультиколлинеарности авторы применяют метод главных компонентов.

\section{Эволюция информационной прозрачности российских компаний и ее возможные причины}

В рамках дискуссий на конференции был поставлен вопрос об изменениях в уровне раскрытия и прозрачности информации российских компаний. Эти вопросы прежде всего освещались в докладе, посвященном результатам исследования специалистов S\&P по крупнейшим 80 российским компаниям, имеющим наиболее ликвидные акции, и докладе Сеттлза А.. 61 компания включена в исследование повторно после 2006 г. Поскольку в настоящее время в России боле 300 публичных компаний, используемая выборка может быть нерепрезентативна с точки зрения всех компаний. Она даст завышенное среднее значение информационной прозрачности, поскольку крупнейшие компании чаще выходят на мировые рынки капитала, где требования к прозрачности выше. Но специалисты S\&P отмечают, что на выбранные ими компании приходится $80 \%$ капитализации фондового рынка и значительная часть активов и объема операций, поэтому они считают возможным использовать эту выборку.

Общий индекс информационной прозрачности российских компаний считался как простое среднее баллов всех компаний в выборке. Изменение транспарентности оказалось малым и статистически незначимым - рост составил 1,1 процентных пункта по всем компаниям и 1 процентный пункт по компаниям, вошедшим в выборку повторно. Российские компании, достигая какого-то определенного уровня прозрачности, позволяющего им получить листинг на иностранных биржах, на нем и останавливаются, и этот уровень может быть повышен лишь при ужесточении нормативных требований или появлении новых рыночных стимулов. Индекс транспарентности компаний, взвешенный по капитализации, и вовсе сократился на 1 процентный пункт, в то время как годом ранее он вырос на 4 процентных пункта по сравнению с 2005 г.

При этом отраслевые характеристики информационной прозрачности неоднородны. Лучшими показателями прозрачности характеризуются телекоммуникационная (71 п.) и металлургическая (65 п.) отрасли, в то время как хуже всего ситуация обстоит в машиностроительной (37 п.) отрасли и в отрасли информационных технологий. «Разброс» показателя меры прозрачности российских компаний изменился незначительно: лидер рейтинга прозрачности компания МТС опережает последнюю компанию в рейтинге, «Башнефть», на 57 п. против 58 п. годом ранее. Нефтегазовая отрасль с величиной индекса 61 находится в середине рейтинга прозрачности отраслей.

Повышению прозрачности способствует разворачивание процессов IPO. Как отмечает в докладе Сеттлз А., особенно сильный эффект должен наблюдаться при IPO на зарубежных площадках. Компании, выпускающие депозитарные расписки, сталкиваются не только с более высокими требованиями к информационной прозрачности со стороны западных бирж. Им необходимо представить себя в выгодном свете зарубежным инвесторам, отношение которых к качеству корпоративного управления в российских компаниях традиционно скептично. По словам Сеттлза, «в тех странах, где уровень корпоративного управления в 
целом низок, фирмы, внедрившие у себя лучшие практики, получают большое преимущество».

Исследование специалистов S\&P показало, что компании, вышедшие на IPO в 2007 г. или намеренные сделать это в ближайшее время, резко повысили свою информационную прозрачность. Так, ТГК-5 прибавила 19 процентных пункта., рейтинг ТГК-9 вырос на 13 процентных пунктов, ОГК-5 увеличила информационную прозрачность на 11 процентных пунктов. Холдинг РАО ЕЭС добился рекордных результатов, увеличив прозрачность на 20 процентных пунктов. Это объясняется тем, что от качества раскрытия информации самим холдингом зависит успешность IPO его дочерних компаний.

Следует заметить, что IPO оказывает долгосрочный положительный эффект на уровень информационной прозрачности. В год IPO резкое увеличение прозрачности объясняется необходимостью соответствовать критериям иностранной биржи, а также выпуском всеобъемлющего информационного меморандума. В последующие годы меморандум отсутствует, однако компании стремятся восполнить информационный пробел за счет иных источников: подробных годовых отчетов, публикации Устава и других внутренних положений, более своевременной публикации отчетности по международным стандартам.

Так, для «Мечела», проведшего IPO на NYSE в 2004 г., средний балл вырос с 29 п. более чем до 70 и до сих пор остается на столь же высоком уровне. ММК, ТМК и «Северсталь» также повысили свой рейтинг после выхода на LSE, однако для них эффект был не столь внушительным. Это обусловлено, во-первых, менее строгими требованиями к листингу на лондонской бирже по сравнению с американскими; а во-вторых, тем, что компании прежде размещали акции на национальных площадках и потому имели довольно высокий рейтинг прозрачности.

Сеттлз А. приводит еще один аргумент, объясняющий, почему компаниям, выходящим на IPO одновременно на российской и на зарубежной площадках (по российским законам, проводить IPO за рубежом без листинга на национальной бирже нельзя), требуется активнее повышать свою информационную прозрачность. Фирмы, уже котирующиеся на РТС или ММВБ, имеют историю отношений с внешними миноритарными собственниками, которую зарубежные инвесторы до определенной степени принимают во внимание, когда определяют спрос на депозитарные расписки. В то же время рынок ничего не знает о практике корпоративного управления в компаниях, которые впервые выходят на IPO и делают это за рубежом, поэтому требования к их информационной прозрачности выше.

$\mathrm{B}$ рамках исследования S\&P изучалась важная взаимосвязь между стоимостью компании и ее информационной прозрачностью. При расчете меры стоимости компании производилась корректировка на размер компании, поэтому в качестве зависимой переменной использовался мультипликатор EV/Sales (стоимость компании в отношении к продажам). Зависимой переменной был индекс информационной прозрачности. Исследование проводилось по 80 компаниям, для которых рассчитывался индекс прозрачности S\&P, методом оценки регрессионного уравнения была экспоненциальная регрессия.

Положительная взаимосвязь между стоимостью и прозрачностью, как отмечалось выше в исследовании специалистов S\&P, следует из теории корпоративного управления. Но она может искажаться влиянием на прозрачность других факторов, таких как перспективы развития бизнеса, ситуация в отрасли, на рынке, политика государства, что также подчеркивалось и в докладе Гуриева C. Специалисты S\&P, взяв в качестве меры стоимости компании мультипликатор EV/Sales и использовав экспоненциальную регрессию, получили положительную, хотя и довольно слабую $\left(\mathrm{R}^{2}=27 \%\right)$ взаимосвязь между стоимостью и прозрачностью. Однако их анализ не учитывал влияние отраслевой принадлежности компаний на мультипликатор, что могло привести как к появлению кажущейся взаимосвязи, так и к ослаблению значимости регрессии. Если компании отраслей с высокой прозрачностью (телекоммуникации, металлы) вне зависимости от уровня раскрытия информации характеризуются высокими мультипликаторами EV/Sales, а машиностроение - 
традиционно низкими мультипликаторами, полученные специалистами S\&P результаты могут не иметь никакой объясняющей силы.

Исследование Сеттлза А. также показывает положительную взаимосвязь между оценкой компании внешними инвесторами и ее информационной прозрачностью. Автор использует информацию по 16 IPO российских компаний, осуществленных на Лондонской бирже в период с 2003-го по 2007 г. Данные подтверждают, что акции компаний, которые поддерживали высокие стандарты корпоративного управления и прозрачности в период листинга и сохраняли прозрачность отчетности и структуры собственности после листинга, демонстрировали более высокую доходность.

Наконец, исследование S\&P позволило выявить компоненты прозрачности, информация по которым раскрывается российскими компаниями хуже всего. В число таких компонентов больше не входит дивидендная политика (доля компаний, раскрывших информацию о ней, выросла до 45\%). Это можно объяснить тем, что компании понимают важность раскрытия такой информации для миноритарных акционеров, поскольку получение дивидендов - едва ли не единственный для последних способ реализовать право собственности на акции компании.

Хуже всего российские компании раскрывают информацию по двум вопросам политика ротации аудитора и условия договора с генеральным директором, хотя прозрачность по обоим показателям немного повысилась по сравнению с 2006 г. Своевременность публикации финансовой отчетности российских компаний также низкая, она не соответствует лучшей мировой практике. Анализ S\&P показывает, что опубликовать отчетность по МСФО или US GAAP в течение четырех месяцев отчетного года, т.е. до конца апреля 2007 г., успела всего 21 компания, или 26\% выборки. Более-менее приемлемой является публикация отчетности по международным стандартам до годового собрания акционеров, которое проводится, как правило, в конце июня. Здесь ситуация лучше: отчетность по МСФО/US GAAP выпускают 42 фирмы (60\% выборки).

В качестве возможной причины стагнации уровня прозрачности российских компаний в исследовании Дурнева А. и Гуриева С. рассматривается феномен «ресурсного проклятия». В докладе Гуриева С. отмечается, что негативная зависимость между ресурсным богатством страны и темпами экономического роста, получившая название «ресурсного проклятья», подтверждается многими исследованиями. Но авторы этих работ не добились успеха в выявлении механизма, через который работает «ресурсное проклятье». Дурнев А. и Гуриев С. предлагают одно из возможных объяснений: компании в отраслях, богатых природными ресурсами, сталкиваются с большим риском экспроприации со стороны государства и имеют стимул снизить свою информационную прозрачность. Более низкая прозрачность, в свою очередь, ведет к менее эффективному распределению капитала и торможению экономического роста.

Прибыльность фирмы может объясняться двумя группами причин: компетенцией менеджмента и внешними условиями - благоприятной ценовой конъюнктурой конечного продукта, в частности нефти. В первом случае государству невыгодно производить экспроприацию собственности, потому что в результате нее компетенции будут потеряны, нематериальные активы уничтожены, и прибыльность фирмы сильно снизится. И наоборот, переход компаний, сильно зависящих от внешней конъюнктуры, в руки государства, не помешает ему получать прибыль при сохранении благоприятной конъюнктуры. Чем лучше внешняя конъюнктура (в частности, цены на нефть), тем выше риск экспроприации. Хороший способ защититься от экспроприации - сделать компанию как можно более непрозрачной.

Дурнев А. и Гуриев С. справедливо утверждают, что негативная зависимость между ресурсным богатством и прозрачностью компаний сильнее в странах, правительства которых характеризуются более «грабительским» (predatory) поведением. Они измеряют склонность к такому поведению с помощью агрегатного индекса. Он включает индексы коррумпированности и силы закона (rule of law) Transparency International, защиты прав 
собственности, свободы конкуренции, качества бюрократических процедур и другие, полученные из Economist Intelligence Unit. Другие меры склонности государства к экспроприации включают политическую принадлежность лидера страны (левая или правая) и две фиктивные переменные: демократичность против авторитаризма ( 1 в первом случае, 0 - во втором) и переменную для года парламентских или президентских выборов.

Авторы проводят исследование по отраслевым данным 49 развивающихся стран за 16 лет (1990-2005), не включая Россию. Основной в их работе является зависимость уровня информационной непрозрачности от склонности правительства к экспроприации, степени уязвимости отрасли к экспроприации и цены на нефть. Поскольку, согласно теоретической модели, компании сокращают информационную прозрачность под совместным влиянием трех перечисленных факторов, в регрессии в качестве независимых переменных используются их произведения. Группа контрольных переменных включала прежде всего, степень потребности компании во внешнем финансировании. Чем выше эта потребность, тем сильнее для компании необходимость повысить прозрачность раскрытия информации, невзирая на риск экспроприации.

Регрессионное уравнение в модели Дурнева А. и Гуриева С. имеет вид:

$$
\begin{aligned}
& \text { OPACITY }_{j i}^{c}=a_{j}+\delta_{c}+\eta_{i}+\beta_{1} \text { EXPR }_{j t} * O I L_{-} \text {PRICE }_{t} * L^{c}{ }_{t}+ \\
& +\beta_{2} \text { EXPR }_{j t} * O I L_{-} \text {PRICE }_{t}+\beta_{3} \text { EXPR }_{j t} * L^{c}{ }_{t}+\gamma \text { CONTROLS }{ }_{j t}+\varepsilon^{c}{ }_{j t}
\end{aligned}
$$

где OPACITY ${ }_{\mathrm{j}, \mathrm{t}}^{\mathrm{c}}$ - индекс непрозрачности компаний отрасли ј в стране с в году $\mathrm{t}$;

$\mathrm{EXPR}_{\mathrm{j}, \mathrm{t}}$ - степень уязвимости отрасли $\mathrm{j}$ в году $\mathrm{t}$ к экспроприации (измеряется как чувствительность прибыльности компаний отрасли к цене на нефть как компоненте внешних условий, наиболее сильно воздействующей на прибыльность компаний);

OIL_PRICE $\mathrm{t}_{\mathrm{t}}$ - цена на нефть в году $\mathrm{t}$;

$\mathrm{L}_{\mathrm{t}}^{\mathrm{c}}-$ индекс склонности государства в стране с к экпроприации в году $\mathrm{t}$;

CONTROLS - группа контрольных переменных.

Дурнев А. и Гуриев С. находят эмпирическое подтверждение своей теоретической гипотезе: знак коэффициента $\beta_{1}$ во всех альтернативных спецификациях регрессии (включающих разные меры непрозрачности, которые были описаны выше) положителен и значим, при этом коэффициент перед мерой потребности фирмы во внешнем финансировании всегда отрицателен. Чтобы смягчить проблему принципал - агент и сделать себя более привлекательными для инвесторов, компаниям приходится повышать уровень информационной прозрачности. Что любопытно, непрозрачность фирм значимо увеличивается в год выборов, поскольку это время связано с повышенной неопределенностью относительно государственной политики и ростом вероятности экспроприации.

Авторы признают, что полученные ими эмпирические результаты могут иметь ряд альтернативных объяснений. Во-первых, компании с низким уровнем информационной прозрачности и высокой зависимостью от природной ренты (например, государственные монополии) могут лоббировать избрание «грабительского» государства, которое будет смотреть сквозь пальцы на ущемление прав миноритариев в этих компаниях. Однако значимое влияние на непрозрачность оказывает переменная года выборов, на которую компании-лоббисты повлиять не могут, поэтому гипотеза об обратной зависимости непрозрачности и склонности государства к экспроприации должна быть отвергнута. Вовторых, благоприятная внешняя конъюнктура может вести к стабилизации котировок акций компании и, следовательно, к повышению определенной выше меры информационной непрозрачности и общего индекса непрозрачности. Дурнев А. и Гуриев С. показывают, что два других компонента индекса непрозрачности (инсайдерская и непрозрачность отчетности) также отрицательно зависят от ресурсного изобилия, что делает альтернативное объяснение неприемлемым. 


\section{Заключение}

Прозрачность раскрытия информации - важная часть корпоративного управления. Увеличение прозрачности ослабляет конфликт принципал - агент в корпорации, оно выгодно как внешним инвесторам, так и инсайдерам - менеджменту, совету директоров, существующим мажоритарным акционерам. Особенно важное значение прозрачность приобретает при выходе компании на IPO. Размещение компаний из развитых стран на зарубежных площадках предполагает еще более высокие требования инвесторов к раскрытию информации и повышает прозрачность компании.

Тем не менее проведенное Службой рейтингов корпоративного управления S\&P в 2007 г. исследование показало, что индекс информационной прозрачности российских компаний стагнирует. Положительный вклад в него вносят в основном компании, вышедшие в течение года на IPO или ведущие подготовку к нему. Последнее наблюдение подтверждает работа Сеттлза А., который изучал IPO 16 российских компаний, проведенных на LSE в 2003-2007 гг. Достигнув определенного уровня прозрачности, позволяющего успешно пройти листинг на одной из западных площадок, российские компании не стремятся дальше повышать свою информационную прозрачность, хотя это могло бы увеличить их стоимость. Многие компании с большим опозданием публикуют отчетность по МСФО или US GAAP, что делает ее нерелевантной для инвесторов. Но положительная зависимость между стоимостью компании и ее прозрачностью прослеживается.

Возможное объяснение такому положению дел предлагают Дурнев А. и Гуриев С.. Они отмечают, что увеличение прозрачности имеет не только положительные, но и негативные последствия: прибыльная компания с высоким уровнем прозрачности может стать жертвой национализации или другой формы экспроприации. Эта причинно-следственная связь особенно сильна для компаний с высокой зависимостью от внешней конъюнктуры, к которым относится большинство российских корпораций. Риск экспроприации сильно возрастает в годы выборов, потому что смена власти порождает неопределенность. Поэтому слабая динамика индекса прозрачности S\&P в 2007 г. в сравнении со значительным ростом год назад может быть обусловлена приближением выборов в Государственную Думу. Расчет индекса прозрачности S\&P проводился на середину 2007 г., по итогам всего года его значение, вероятно, было бы еще ниже. Неблагоприятная конъюнктура мировых финансовых рынков заставляет российские компании откладывать IPO и выпуски еврооблигаций на неопределенный срок, что ослабляет стимулы к повышению информационной прозрачности.

\section{Список литературы}

1. Black B.S., Love I., Rachinsky A. Corporate Governance and Firms' Market Values: Time Series Evidence from Russia / Emerging Markets Review, 2006, № 7, p. 361-379.

2. Durnev A., Guriev S. The Resource Curse: A Corporate Transparency Channel / Paper presented at the Second International Conference «Corporate Governance and Sustainable Business Development: Strategic Roles of Board of Directors», November 2007.

3. Settles, A. The Corporate Governance Changes Due to Exposure to the International Capital Market: The Role of IPOs, SPOs, and Debt Issuance Experience of Russia Firm Practice 2003 - 2007/ Paper presented at the Second International Conference «Corporate Governance and Sustainable Business Development: Strategic Roles of Boards of Directors /, November 2007.

4. Zaman A., Collier P.A. Convergence in European Corporate Governance: The Audit Committee Concept / Corporate Governance: An International Review, 2005, № 6, p. 753-768.

4. Служба рейтингов корпоративного управления Standard\&Poor's при поддержке Фондовой биржи ММВБ. Исследование информационной прозрачности российских компаний в 2007 г.: Значительные изменения в десятке лидеров. Доклад, представленный на 
Второй международной конференции «Корпоративное управление и устойчивое развитие бизнеса: стратегические роли советов директоров», ноябрь 2007. 